\title{
THE EFFECTS OF SOME MEDICINAL PLANTS WITH INSULIN ON THE INFLAMMATORY AND METABOLIC RESPONSES IN DOGS WITH INDUCED DIABETES MELLITUS
}

\author{
Hany HASSAN ${ }^{1 \otimes} \otimes$, Ahmed ZAGHAWA ${ }^{2}$, Mahmoud ALY ${ }^{1}$, Ahmed KAMR $^{1}$, Mohamed NAYEL ${ }^{2}$, Mostafa Abd El Gaber \\ MOHAMED ${ }^{3}$, Ali ABDELAZEIM ${ }^{1}$ and Basma HASSAN 1 \\ ${ }^{1}$ Department of Animal Medicine and Infectious Diseases (Animal Medicine), Faculty of Veterinary Medicine, University of Sadat City, Egypt \\ 2 Department of Animal Medicine and Infectious Diseases (Infectious Diseases), Faculty of Veterinary Medicine, University of Sadat City, Egypt \\ ${ }^{3}$ Department of Animal Pathology, Faculty of Veterinary Medicine, University of Sadat City, Egypt \\ Email: Hanyhassan1959@gmail.com \\ Supporting Information
}

\begin{abstract}
The goals of this study were to determine biochemical biomarkers and histopathological changes in addition to exploring insulin as mono-therapy as well as insulin plus some medical plants include Garlic, Fenugreek (Trigonella foenum-graecum L.) and Black seeds (Nigella Sativa) as feed additives in dogs with experimentally induced diabetes mellitus (DM). A total of 15 clinically apparent healthy adult dogs were involved in this study and divided into group 1: included five normal adult dogs served as non-diabetic control group, group 2: Included five adult dogs that were subjected to experimentally diabetes mellitus by intravenous (IV) injection of alloxan and treated by with insulin only and group 3: Included five adult dogs that were subjected to experimentally diabetes mellitus by IV injection of alloxan and treated by with insulin plus once daily supplement with herbal therapy. In conclusions, the therapeutic effects of some medical plants include Garlic, Fenugreek (Trigonella foenum-graecum L.) and Black seeds (Nigella Sativa) increased the potency and glycemic control of insulin in animals with diabetes mellitus. Therefore, it is recommended adding the previously mentioned herbs as feed additives to improve the potency of insulin to control DM in dogs.
\end{abstract}

Keywords: Dogs; Diabetes mellitus, Alloxan hydrate; Insulin; Insulin with herbal therapy

\section{INTRODUCTION}

Diabetes mellitus (DM) is a common disorder that has been associated with increased morbidity and mortality rate and defined as a metabolic disorder characterized by chronic hyperglycemia and decreased in insulin secretion, insulin action, or both, resulting in impaired carbohydrate, lipid and protein metabolism (Ti Zhang et al., 2006; Ettinger et al., 2017).

Clinical signs of DM appear when blood glucose concentrations of 180-220 mg/dl in dogs and 220-270 mg/dl in cats (Nelson and Reusch, 2014). Diabetic dogs and cats are hyperglycemic and glucosuric with clinical signs of polyuria, polydipsia polyphagia, and weight loss as well as other metabolic alterations including hepatic lipidosis, hepatomegaly, hypercholesterolemia, hypertriglyceridemia, increased catabolism and ketoacidosis (Rucinsky et al., 2010).

The acute phase response is a non-specific inflammatory reaction after any tissue damage and is associated with decreased concentrations of negative acute phase protein such as albumin or transferrin, and/or increased concentrations of positive acute phase protein that include C-reactive protein (CRP), serum amyloid A (SAA), haptoglobin $(\mathrm{Hp}), \alpha-1$-acid glycoprotein, and ceruloplasmin. Most positive acute phase protein, are glycoproteins synthesized by hepatocytes and their secretion is potentiated by pro-inflammatory cytokines (Cero'n et al., 2005). However, the novel role of acute phase protein in DM need further investigation.

Oral hypoglycemic drugs with insulin are used as medications to control diabetes mellitus (Mesa, 2014). Herbal therapy are used by about $60 \%$ of the world's population without side effects compared to the traditional plants and play a crucial role in controlling DM, these include Allium sativum, Eugenia jambolana, Momordica charantia, Ocimum sanctum, Phyllanthus amarus, Pterocarpus marsupium, Tinospora cordifolia, C. indica, Helicteres isora, Stevia rebaudiana, Gymnema sylvestre, Enicostemma littorale Blume (Patel et al., 2012). Thereby, the role of herbal therapy in DM needs to be elucidated in pet animals.

The aims of this study were to determine the clinical picture, biochemical and histopathological changes on the experimentally-induced diabetic dogs, investigate a recent novel biomarkers in diagnosis of affected animals like determination of acute-phase proteins in addition to investigating insulin as mono-therapy as well as insulin plus some medical plants include Garlic tablets, Fenugreek and Nigella Sativa as feed additives. 


\section{MATERIALS AND METHODS}

\section{Animals' criteria and ethical approval}

A total number of 15 clinically healthy adult dogs were included in this study. Their age ranged from $2.3 \pm 0.3$ years old and their body weights from $12.5 \pm 0.5 \mathrm{~kg}$. They were fed on a diet composed of meat, bones and bread twice daily free access to sufficient tap water. The animals were placed in separated metal cages and kept under the same environmental, nutritional and hygienic condition throughout the period of experiment (4 weeks). All animals were clinically healthy based on physical examination, as well as, some laboratory investigation as: serum biochemistry analysis and urinalysis, to make sure that all dogs under the experimentation are free from both external and internal parasite, plus blood parasite and apparently healthy.

The present study was carried at veterinary hospital of faculty of veterinary medicine Sadat City University. And these animals are divided into three main groups as following: group 1: included five normal adult dogs served as non-diabetic control group and their health condition confirmed by physical and biochemical evaluation at day (D) 1,2 and 3 during induction and treatment. Group 2 included five adult dogs that were subjected to experimentally diabetes mellitus by IV injection of alloxan and treated by insulin (MIXTARD $\left.{ }^{\circledR}\right) \mathrm{S} / \mathrm{C}$ in a dose rate of $(1.0 \mathrm{IU} / \mathrm{kg}$ body weight) once daily for one month and evaluated at D1,2 and 3 during induction and treatment (Hess and Ward, 2000). Group 3: Included five adult dogs that were subjected to experimentally diabetes mellitus by IV injection of alloxan and treated by insulin (MIXTARD ${ }^{\circledR}$ ) $\mathrm{S} / \mathrm{C}$ in a dose rate of (1.0 IU/ $\mathrm{kg}$ body weight) once daily for one month in addition to Garlic (TOMIX $\left.{ }^{\circledR}\right)$ one tablet orally plus feed additives purchased from local market $(1.5 \mathrm{~g} / \mathrm{kg} /$ day of Fenugreek seeds powder $+2 \mathrm{~g} /$ day of Nigella sativa seeds and evaluated at D1 and 2 of induction and treatment. All the procedures in this study was approved by animal Ethics Committee for the Care and Use of Animals in Education and Scientific Research, University of Sadat city (Approval number VUSC-007-1-19).

\section{Experimental induction of diabetes mellitus in dogs}

Dogs were fasted for at least $12 \mathrm{hr}$. before the experimental induction of diabetes, which was produced by single intravenous administration of Alloxan hydrate at dose rate of $(35 \mathrm{mg} / \mathrm{kg})$ body weight dissolved in $5 \mathrm{~cm}$ of normal saline, then 2-3 days later, the dogs showed a fasting blood glucose concentrations of $>10 \mathrm{mmol} \mathrm{L}^{-1}$ (Christopher et al., 2006), blood glucose concentrations were measured frequently for 7days, by using a (Easy touch) ${ }^{\circledR} \mathrm{G}$, blood glucose monitoring system. Blood glucose concentrations (over $200 \mathrm{mg} / \mathrm{dl}$ ) were considered diabetic. Within 2-3 days, of clearance of clinical symptoms the diabetic dogs began receiving the insulin subcutaneous injections in a dose rate of rate (1.0 IU)/ $\mathrm{kg}$ body weight once daily (Hess and Ward, 2000). All dogs had free access to water at all times; the administered diet was composed of a low carbohydrate and high protein and fiber twice daily, at a fixed time before insulin administration to ensure dietary intake before onset of insulin action. All dogs were evaluated by clinical examination and laboratory studies before and after injection of alloxan at (Zero, $2^{\text {nd }}, 4^{\text {th }}, 7^{\text {th }}, 9^{\text {th }}, 11^{\text {th }}, 14^{\text {th }}, 18^{\text {th }}$ days).

\section{Samples}

Blood samples were obtained from jugular vein and cephalic vein by sterile needle with large bore. The blood samples were collected without anticoagulant for obtaining clear non-hemolyzed serum by centrifugation of the blood sample at $3000 \mathrm{rpm}$. For 5 minutes. The clear sera were aspirated carefully by Pasteur pipette and transferred into clean dry labeled Eppendorf tubes and stored at-20 c till examination. Urine samples were collected by catheterization under aseptic condition for urine analysis using urine test stripes according to Brenner et al. (2009). Post mortem liver and pancreatic specimen samples were collected from dead dogs about $0.5 \mathrm{~cm}$ thickness at the end of the experiment for histopathology.

\section{Measurements}

Serum glucose concentrations $(\mathrm{mg} / \mathrm{dl})$ was determined colometrically using of special kits according to the method described by Trinder (1969). Serum insulin concentrations $(\mathrm{mg} / \mathrm{dl})$ was determined by radioimmunoassay method using radioimmunoassay kits according to the method described by Wilson and Miles (1977). Serum alanine aminotransferases (ALT) concentrations (U/L) was determined according to the method that described by Young (1990). Serum aspartate aminotransferases (AST) concentrations (U/L) was determined according to the method that described by Reitman and frankle (1957). Serum alkaline phosphatases (ALP) (U/L) was determined according to the method that described by Henderson et al. (2001). Serum cholesterol concentrations (g/dl) was determined by enzymatically method according to Meiattini et al. (1978). Serum triglycerides concentrations $(\mathrm{g} / \mathrm{dl})$ was determined by enzymatically method according to Kaplan et al. (1984). Serum HDL and cholesterol and LDL cholesterols $(\mathrm{mg} / \mathrm{dl})$ were determined by precipitation method according to Cunical Chemistry (1995). Serum albumin concentrations (g/dl) was determined calorimetrically by using dye-binding technique with Bromcresol green according to Webster (1974). Serum amyloid A concentrations (mg/dl) was determined according to the method described by Supranee jitpean et al. (2014). Serum c-reactive proteins concentrations $(\mu \mathrm{g} / \mathrm{ml})$ was determined according to the method that described by Fransson et al. (2007). Serum haptoglobin concentrations $(\mathrm{g} / \mathrm{l})$ was determined according to the method described by Sima Sahinduran et al. (2016). 


\section{Histopathological examination}

Samples taken from pancreas and liver were collected immediately after death and fixed in neutral buffered formalin $10 \%$. After complete fixation, the specimens were dehydrated, infiltrated and embedded in paraffin. The paraffin blocks were sectioned at 5-7 microns thickness. Tissue were stained with haematoxylin and eosin stain (Thomas and Richter, 1984).

\section{Statistical analysis}

Data was normally distributed according to Shapiro-Wilk test and expressed as mean with standard errors. Data was analyzed using T-test and repeated measure ANOVA using SPSS software. Significance was set at $P<0.05$. Area under the curve (ROC) was calculated to determine the sensitivity and specificity of acute phase protein in dogs with induced diabetes mellitus by using SPSS.

\section{RESULTS}

\section{Clinical findings between healthy and diabetic groups}

The physical examination concerning body temperature revealed non- significant changes between groups, while heart rate revealed a significant decrease in both diabetic groups ( 2 and 3 ) compared with those of normal control group 1 (Table 1).

\section{Urine analysis between diabetic and control groups}

The diabetic dogs had glycosuria and proteinuria. However, no change in the urine PH was observed compared with normal dogs (Table 1).

\section{Table 1 - Clinical findings and urine analysis in clinically healthy and in experimentally diabetic dogs}

\begin{tabular}{|c|c|c|c|}
\hline Variables & Groups & Control & After induction \\
\hline Body temperature $\left(\mathrm{C}^{\circ}\right)$ & & $37.5 \pm 0.33^{a}$ & $38.3 \pm 0.80^{a}$ \\
\hline Heart Rate (Beat/Min) & & $80.5 \pm 2.2^{a}$ & $65.4 \pm 3.6^{b}$ \\
\hline pH & & 5 & 5 \\
\hline Glucose & & - & +++ \\
\hline Protein & & - & +++ \\
\hline
\end{tabular}

Biochemical analysis between diabetic and control groups at $1^{\text {st }}$ week of induction

Table 2 illustrated that serum insulin concentrations were not statistically significant at D1 in all groups, but decreased in concentrations at D2 and D3 in group 2 as well as group 3 compared to control $(P<0.05)$. Serum glucose concentrations were not changed significantly at D1 in all groups, but its concentrations reached its peak at D2, D3 of induction in both groups 2 and 3 compared to control $(P<0.05)$. Serum enzymatic activities of liver including (ALP, AST and ALT) were not statistically different at first day of induction of diabetes mellitus in groups 2 and 3 than control $(P>0.05)$, but significantly elevated at D2 and D3 of induction in groups 2 and 3 compared with control $(P<0.05)$. Serum albumin concentrations were not significantly different at D1 and D2 of induction however, its concentration were elevated at D3 of induction compared to control $(P<0.05)$. Triglycerides and cholesterol concentrations were not statistically different at first day of induction of diabetes mellitus in group 2 as well as group 3 compared to control group1 $(P>0.05)$, but significantly elevated at D2 and D3 of induction in both groups 2 and 3 compared with control group1 $(P<0.05)$. Low density lipoprotein $(L D L)$ and High density lipoprotein $(H D L)$ concentrations were not significantly different at D1 of induction in all groups, but serum LDL were elevated and HDL were reduced at D2 and D3 of induction in both groups 2 and 3 compared to control $(P<0.05)$. SAA, CRP and haptoglobin concentrations were not statistically different at first day of induction of diabetes mellitus in groups 2 and 3 than control $(P>0.05)$. However, SAA, CRP and haptoglobin concentrations were significantly elevated at D2 and D3 of induction in groups 2 and 3 compared with control $(P<0.05)$ as shown in Table 2.

\section{Biochemical analysis between diabetic and control groups at $1^{\text {st }}$ week of treatment and $2^{\text {nd }}$ week of induction}

Serum insulin concentrations during 1st week of treatment were significantly lower in both treated groups at D1 and D2 than control. However, its concentrations start to increase significantly in group 3 treated with insulin + herbal therapy than group 2 treated with insulin alone $(P<0.05)$. Serum glucose concentration during $1^{\text {st }}$ week of treatment still show significant increase in both treated groups at D1, D2 and D3 than control $(P<0.05$, Table 3$)$. Serum concentrations of ALP were significantly higher in both treated groups compared to control $(P<0.05)$. Serum ALT and AST were elevated significantly in both treated groups compared to control, but their elevation in group 3 treated with insulin + herbal therapy were significantly lower than group 2 treated with insulin only $(P<0.05$, Table 3$)$. Serum albumin concentrations 
were significantly elevated at D1 and D2 of treatment in both treated groups than control one. However, its concentration were not statistically significant at D3 of treatment in both treated groups compared to control group $(P<0.05$, Table 3$)$. Serum triglycerides concentrations were elevated significantly in both treated group at D1 and D2 compared to control one, but their elevation in D3 in treated dogs with insulin + herbal therapy were significantly lower than in dogs treated with insulin only $(P<0.05)$. Serum cholesterol concentrations were significantly elevated at D1, D2 and D3 in two treated groups compared to control $(P<0.05)$. Serum LDL were elevated and HDL were reduced significantly at D1, D2 and D3 of treatment in both treated groups compared to control group $(\mathrm{P}<0.05$, Table 3 ). C-reactive protein and haptoglobin concentrations were significantly elevated at D1, D2 and D3 in two treated groups compared to control $(P<0.05)$. However, SAA were elevated in D1, D2 in two treated groups compared to control except at D3 .which, SAA were not significantly different in the two treated group compared to control group $(P>0.05$, Table 3$)$.

Table 2 - Biochemical analysis between diabetic and control groups at $1^{\text {st }}$ week of induction

\begin{tabular}{|c|c|c|c|c|c|}
\hline \multirow[b]{2}{*}{ Variables } & \multirow[b]{2}{*}{ Weeks } & \multirow[b]{2}{*}{ Days } & \multirow[b]{2}{*}{ Control } & \multicolumn{2}{|c|}{ After induction without treatment } \\
\hline & & & & Insulin & $\begin{array}{c}\text { Insulin with } \\
\text { herbal therapy }\end{array}$ \\
\hline \multirow{3}{*}{ Insulin ( $\mu l \mathrm{u} / \mathrm{mL})$} & \multirow{3}{*}{$1^{\text {st }}$ week } & D1 & $10.3 \pm 0.6^{a}$ & $10.2 \pm 0.7^{a}$ & $10.1 \pm 0.9^{a}$ \\
\hline & & D2 & $10.2 \pm 0.4^{a}$ & $6.7 \pm 0.4^{a}$ & $6.7 \pm 0.1^{\mathrm{a}}$ \\
\hline & & D3 & $10.5 \pm 0.6 \mathrm{a}$ & $4.4 \pm 0.3^{b}$ & $4.5 \pm 0.2^{b}$ \\
\hline \multirow{3}{*}{ Glucose (mg/dL) } & \multirow{3}{*}{$1^{\text {st }}$ week } & D1 & $95.3 \pm 2.6^{a}$ & $92.2 \pm 5.1^{a}$ & $91.8 \pm 5.6^{a}$ \\
\hline & & D2 & $89 \pm 5.5^{a}$ & $150.4 \pm 8.01^{b}$ & $159.4 \pm 5.6^{b}$ \\
\hline & & D3 & $90.8 \pm 5.6^{a}$ & $203 \pm 7.5^{b}$ & $206.2 \pm 7.3^{b}$ \\
\hline \multirow{3}{*}{$\operatorname{ALP}(u / L)$} & \multirow{3}{*}{$1^{\text {st }}$ week } & D1 & $155.8 \pm 0.7^{a}$ & $153.8 \pm 0.8^{a}$ & $156.4 \pm 0.4^{a}$ \\
\hline & & D2 & $161.6 \pm 0.5^{a}$ & $193.4 \pm 0.6^{b}$ & $198.8 \pm 0.8^{b}$ \\
\hline & & D3 & $160.4 \pm 0.5^{a}$ & $248.6 \pm 0.7^{b}$ & $253.6 \pm 0.12^{b}$ \\
\hline \multirow{3}{*}{$\operatorname{AST}(u / L)$} & \multirow{3}{*}{$1^{\text {st }}$ week } & D1 & $33.8 \pm 2.1^{a}$ & $35.2 \pm 3.2^{a}$ & $32.2 \pm 2.3^{a}$ \\
\hline & & D2 & $32 \pm 3.1^{a}$ & $54.8 \pm 2.3^{b}$ & $57.2 \pm 3.33^{b}$ \\
\hline & & D3 & $36.4 \pm 2.7^{a}$ & $72.2 \pm 3.8^{b}$ & $72.8 \pm 5.9 b$ \\
\hline \multirow{3}{*}{$\operatorname{ALT}(\mathrm{u} / \mathrm{L})$} & \multirow{3}{*}{$1^{\text {st }}$ week } & D1 & $33.4 \pm 1.3^{a}$ & $32.2 \pm 2.1^{\mathrm{a}}$ & $31.6 \pm 2.2^{a}$ \\
\hline & & D2 & $31 \pm 1.6^{a}$ & $54.8 \pm 2.8^{b}$ & $52.6 \pm 3.1^{b}$ \\
\hline & & D3 & $31.2 \pm 1.5^{a}$ & $79.8 \pm 3.8^{b}$ & $74.6 \pm 4.3^{b}$ \\
\hline \multirow{3}{*}{ Albumin (mg/dL) } & \multirow{3}{*}{$1^{\text {st }}$ week } & D1 & $4.3 \pm 0.2^{a}$ & $4.3 \pm 0.3^{a}$ & $4.2 \pm 0.3^{a}$ \\
\hline & & D2 & $4.1 \pm 0.2 a$ & $4.1 \pm 0.4^{a}$ & $4.02 \pm 0.1^{\mathrm{a}}$ \\
\hline & & D3 & $4.3 \pm 0.2^{a}$ & $5.8 \pm 0.2^{b}$ & $6.14 \pm 0.1^{b}$ \\
\hline \multirow{3}{*}{ Triglycerides (mg/dL) } & \multirow{3}{*}{$1^{\text {st }}$ week } & D1 & $125 \pm 1.6^{a}$ & $113.6 \pm 2.1^{\mathrm{a}}$ & $111.4 \pm 3.6^{a}$ \\
\hline & & D2 & $117.4 \pm 4.5^{a}$ & $148.6 \pm 7.7^{b}$ & $141.4 \pm 3.6^{b}$ \\
\hline & & D3 & $117.2 \pm 4.5^{a}$ & $189.4 \pm 8.7^{b}$ & $184.4 \pm 3.6^{b}$ \\
\hline \multirow{3}{*}{ Cholesterol (mg/dL) } & \multirow{3}{*}{$1^{\text {st }}$ week } & D1 & $157.4 \pm 6.4^{\mathrm{a}}$ & $148.1 \pm 4.8^{a}$ & $150.4 \pm 4.8^{\mathrm{a}}$ \\
\hline & & D2 & $155.6 \pm 3.7^{a}$ & $169.4 \pm 4.5^{b}$ & $174.2 \pm 5.1^{b}$ \\
\hline & & D3 & $151.2 \pm 6.01^{\mathrm{a}}$ & $225.2 \pm 8.3^{b}$ & $217.8 \pm 5.8^{b}$ \\
\hline \multirow{3}{*}{$\mathrm{LDL}(\mathrm{mg} / \mathrm{dL})$} & \multirow{3}{*}{$1^{\text {st }}$ week } & D1 & 76.6. $\pm 5.6^{a}$ & $74.2 \pm 3.3^{a}$ & $74.4 \pm 4.4^{a}$ \\
\hline & & D2 & $76.7 \pm 2.9^{a}$ & $108.2 \pm 3.5^{b}$ & $115.8 \pm 2.9^{b}$ \\
\hline & & D3 & $77.8 \pm 2.7 \mathrm{a}$ & $151.8 \pm 2.2^{b}$ & $159 \pm 3.63^{b}$ \\
\hline \multirow{3}{*}{$\mathrm{HDL}(\mathrm{mg} / \mathrm{dL})$} & \multirow{3}{*}{$1^{\text {st }}$ week } & D1 & $58.6 \pm 1.4^{a}$ & $57.4 \pm 6.1^{a}$ & $58.6 \pm 5.1^{a}$ \\
\hline & & D2 & $62.2 \pm 5.5^{a}$ & $50.4 \pm 6.03^{b}$ & $50.8 \pm 4.7^{b}$ \\
\hline & & D3 & $59.6 \pm 5.7^{a}$ & $31.6 \pm 3.8^{b}$ & $32.1 \pm 3.7^{b}$ \\
\hline \multirow{3}{*}{$\mathrm{SAA}(\mu \mathrm{g} / \mathrm{mL})$} & & D1 & $4.7 \pm 0.1^{\mathrm{a}}$ & $5.3 \pm 0.3^{a}$ & $5.1 \pm 0.2^{a}$ \\
\hline & $1^{\text {st }}$ week & D2 & $5.1 \pm 0.2^{a}$ & $7.4 \pm 0.1^{b}$ & $7.5 \pm 0.2^{b}$ \\
\hline & & D3 & $5.16 \pm 0.3^{a}$ & $8.3 \pm 0.3^{b}$ & $8.4 \pm 0.2^{b}$ \\
\hline & & D1 & $3.9 \pm 0.2^{a}$ & $4.1 \pm 0.4^{a}$ & $4.3 \pm 0.3^{a}$ \\
\hline CRP (mg/L) & $1^{\text {st }}$ week & D2 & $4.2 \pm 0.4^{a}$ & $8.3 \pm 0.6^{b}$ & $7.5 \pm 0.1^{b}$ \\
\hline & & D3 & $4.2 \pm 0.4^{a}$ & $10.8 \pm 0.4^{b}$ & $11.4 \pm 0.4^{b}$ \\
\hline & & D1 & $0.96 \pm 0.1^{a}$ & $1.08 \pm 0.2^{a}$ & $0.98 \pm 0.1^{\mathrm{a}}$ \\
\hline Haptoglobin (g/L) & $1^{\text {st }}$ week & D2 & $1.08 \pm 0.2^{a}$ & $2.9 \pm 0.4^{b}$ & $2.9 \pm 0.6^{b}$ \\
\hline & & D3 & $1.12 \pm 0.1^{a}$ & $4.22 \pm 0.4^{b}$ & $5.04 \pm 0.5^{b}$ \\
\hline
\end{tabular}

ALP-alkaline phosphatase; AST-aspartate aminotransferase; ALT- alanine aminotransferase; LDL-low density lipoprotein; HDL- high density lipoprotein; SAA-serum amyloid A; CRP-C-reactive protein. Data are presented as means \pm standard error (S.E).Mean value with different superscript letters in the same row are significantly different at $\mathrm{P}<0.05$. 
Table 3 - Biochemical analysis between diabetic and control groups at $1^{\text {st }}$ week of treatment and $2^{\text {nd }}$ week of induction

\begin{tabular}{|c|c|c|c|c|c|}
\hline \multirow[b]{2}{*}{ Variables } & \multirow[b]{2}{*}{ Weeks } & \multirow[b]{2}{*}{ Days } & \multirow[b]{2}{*}{ Control } & \multicolumn{2}{|c|}{ After induction without treatment } \\
\hline & & & & Insulin & $\begin{array}{c}\text { Insulin with } \\
\text { herbal therapy }\end{array}$ \\
\hline \multirow[b]{2}{*}{ Insulin ( $\mu \mathrm{lu} / \mathrm{mL})$} & \multirow[b]{2}{*}{$2^{\text {nd }}$ week } & D1 & $10.04 \pm 0.3^{a}$ & $3.98 \pm 0.2^{b}$ & $3.94 \pm 0.1^{b}$ \\
\hline & & D2 & $10.18 \pm 0.4^{a}$ & $6.16 \pm 0.3^{b}$ & $6.98 \pm 0.4^{b}$ \\
\hline \multirow[b]{2}{*}{ Glucose (mg/dL) } & \multirow[b]{2}{*}{$2^{\text {nd }}$ week } & $\begin{array}{l}\text { D3 } \\
\text { D1 }\end{array}$ & $\frac{10.50 \pm 0.4^{\mathrm{a}}}{93.0 \pm 1.2^{\mathrm{a}}}$ & $\frac{6.72 \pm 0.1^{b}}{275.2 \pm 3.2^{b}}$ & $\frac{8.44 \pm 0.2^{\mathrm{a}, \mathrm{b}}}{275.6 \pm 4.8^{\mathrm{b}}}$ \\
\hline & & $\begin{array}{l}\text { D2 } \\
\text { D3 }\end{array}$ & $\begin{array}{c}91.80 \pm 1.5^{a} \\
89.0 \pm 1.8^{a}\end{array}$ & $\begin{array}{l}221.80 \pm 4.6^{b} \\
207.40 \pm 3.9^{b}\end{array}$ & $\begin{array}{c}233.60 \pm 5.3^{b} \\
209.0 \pm 4.2^{b}\end{array}$ \\
\hline \multirow[b]{2}{*}{$\operatorname{ALP}(u / L)$} & \multirow[b]{2}{*}{$2^{\text {nd }}$ week } & D1 & $161.6 \pm 3.4^{a}$ & $271.6 \pm 5.6^{b}$ & $281.0 \pm 6.2^{b}$ \\
\hline & & $\begin{array}{l}\text { D2 } \\
\text { D3 }\end{array}$ & $\begin{array}{c}153.80 \pm 3.2^{a} \\
159.0 \pm 3.2^{a}\end{array}$ & $\begin{array}{l}253.60 \pm 4.5^{b} \\
234.20 \pm 7.4^{b}\end{array}$ & $\begin{array}{c}257.0 \pm 6.1^{b} \\
235.60 \pm 5.8^{b}\end{array}$ \\
\hline \multirow[b]{2}{*}{ AST (u/L) } & \multirow[b]{2}{*}{$2^{\text {nd }}$ week } & D1 & $32.0 \pm 1.9^{a}$ & $93.60 \pm 2.1^{b}$ & $93.80 \pm 3.2^{b}$ \\
\hline & & $\begin{array}{l}\text { D2 } \\
\text { D3 }\end{array}$ & $\begin{array}{l}35.20 \pm 2.1^{a} \\
34.40 \pm 2.3^{a}\end{array}$ & $\begin{array}{l}81.80 \pm 3.4^{b} \\
69.80 \pm 3.4^{b}\end{array}$ & $\begin{array}{l}74.20 \pm 2.5^{\mathrm{a}, \mathrm{b}} \\
54.60 \pm 3.6^{\mathrm{a}, \mathrm{b}}\end{array}$ \\
\hline \multirow[b]{2}{*}{$\operatorname{ALT}(\mathrm{u} / \mathrm{L})$} & \multirow[b]{2}{*}{$2^{\text {nd }}$ week } & D1 & $31.80 \pm 1.3^{a}$ & $114.40 \pm 2.5^{b}$ & $105.80 \pm 2.8^{b}$ \\
\hline & & $\begin{array}{l}\text { D2 } \\
\text { D3 }\end{array}$ & $\begin{array}{c}32.20 \pm 1.8^{a} \\
31.0 \pm 1.6^{a}\end{array}$ & $\begin{array}{l}100.4 \pm 3.2^{b} \\
88.80 \pm 2.3^{b}\end{array}$ & $\begin{array}{c}88.60 \pm 3.4^{a, b} \\
66.0 \pm 2.3^{a, b}\end{array}$ \\
\hline \multirow[b]{2}{*}{ Albumin (mg/dL) } & \multirow[b]{2}{*}{$2^{\text {nd }}$ week } & D1 & $4.26 \pm 0.1^{\mathrm{a}}$ & $5.94 \pm 0.3^{b}$ & $6.24 \pm 0.1^{b}$ \\
\hline & & $\begin{array}{l}\text { D2 } \\
\text { D3 }\end{array}$ & $\begin{array}{l}4.26 \pm 0.2^{a} \\
4.66 \pm 0.1^{a}\end{array}$ & $\begin{array}{l}5.56 \pm 0.2^{\mathrm{b}} \\
5.20 \pm 0.2^{\mathrm{a}}\end{array}$ & $\begin{array}{l}5.84 \pm 0.3^{b} \\
5.18 \pm 0.4^{a}\end{array}$ \\
\hline \multirow[b]{2}{*}{ Triglycerides (mg/dL) } & \multirow[b]{2}{*}{$2^{\text {nd }}$ week } & D1 & $111.80 \pm 1.8^{a}$ & $210.4 \pm 2.5^{b}$ & $210.8 \pm 4.1^{b}$ \\
\hline & & $\begin{array}{l}\text { D2 } \\
\text { D3 }\end{array}$ & $\begin{array}{l}113.60 \pm 3.2^{a} \\
117.40 \pm 2.4{ }^{a}\end{array}$ & $\begin{array}{c}191.0 \pm 4.5^{b} \\
176.20 \pm 6.01^{b}\end{array}$ & $\begin{array}{c}180.0 \pm 5.3^{b} \\
157.20 \pm 5.8^{a, b}\end{array}$ \\
\hline \multirow[b]{2}{*}{ Cholesterol (mg/dL) } & \multirow[b]{2}{*}{$2^{\text {nd }}$ week } & D1 & $155.0 \pm 3.2 \mathrm{a}$ & $243.0 \pm 4.6^{b}$ & $237.40 \pm 7.01^{b}$ \\
\hline & & $\begin{array}{l}\text { D2 } \\
\text { D3 }\end{array}$ & $\begin{array}{c}148.0 \pm 4.9 \mathrm{a} \\
153.60 \pm 5.01 \mathrm{a}\end{array}$ & $\begin{array}{l}220.40 \pm 6.2^{b} \\
209.20 \pm 3.5^{b}\end{array}$ & $\begin{array}{l}214.20 \pm 4.3^{b} \\
190.20 \pm 5.1^{b}\end{array}$ \\
\hline \multirow[b]{2}{*}{ LDL (mg/dL) } & \multirow[b]{2}{*}{$2^{\text {nd }}$ week } & D1 & $72.20 \pm 3.1 \mathrm{a}$ & $186.20 \pm 3.4^{b}$ & $183.60 \pm 5.4^{b}$ \\
\hline & & $\begin{array}{l}\text { D2 } \\
\text { D3 }\end{array}$ & $\begin{array}{c}74.20 \pm 4.3 a^{a} \\
78.6 \pm 2.8\end{array}$ & $\begin{array}{l}167.40 \pm 3.7^{b} \\
154.80 \pm 2.5^{b}\end{array}$ & $\begin{array}{l}166.40 \pm 3.8^{b} \\
149.40 \pm 4.2^{b}\end{array}$ \\
\hline \multirow[b]{2}{*}{$\mathrm{HDL}(\mathrm{mg} / \mathrm{dL})$} & \multirow[b]{2}{*}{$2^{\text {nd }}$ week } & D1 & $62.20 \pm 1.4 a$ & $21.80 \pm 5.2^{b}$ & $23.60 \pm 5.6^{b}$ \\
\hline & & $\begin{array}{l}\text { D2 } \\
\text { D3 }\end{array}$ & $\begin{array}{l}58.60 \pm 3.2 \mathrm{a} \\
62.40 \pm 4.2^{a}\end{array}$ & $\begin{array}{c}27.0 \pm 4.1^{b} \\
32.20 \pm 3.7^{b}\end{array}$ & $\begin{array}{c}30.40 \pm 5.3^{b} \\
40.0 \pm 4.6^{b}\end{array}$ \\
\hline \multirow{3}{*}{$\mathrm{SAA}(\mu \mathrm{g} / \mathrm{mL})$} & \multirow{3}{*}{$2^{\text {nd }}$ week } & D1 & $5.3 \pm 0.2^{a}$ & $9.34 \pm 0.6^{b}$ & $10.42 \pm 0.8^{b}$ \\
\hline & & D2 & $5.08 \pm 0.4 \mathrm{a}$ & $7.22 \pm 0.6 b$ & $8.24 \pm 0.3^{b}$ \\
\hline & & D3 & $5.28 \pm 0.1 \mathrm{a}$ & $6.30 \pm 0.3^{a}$ & $6.36 \pm 0.2^{a}$ \\
\hline \multirow{3}{*}{ CRP (mg/L) } & \multirow{3}{*}{$2^{\text {nd }}$ week } & D1 & $3.98 \pm 0.1^{\mathrm{a}}$ & $17.60 \pm 1.2^{b}$ & $16.80 \pm 1.02^{b}$ \\
\hline & & D2 & $4.34 \pm 0.2 \mathrm{a}$ & $15.0 \pm 1.01^{b}$ & $14.20 \pm 2.1^{b}$ \\
\hline & & D3 & $4.20 \pm 0.1^{a}$ & $12.80 \pm 0.8^{b}$ & $11.40 \pm 0.7^{b}$ \\
\hline \multirow{3}{*}{ Haptoglobin (g/L) } & \multirow{3}{*}{$2^{\text {nd }}$ week } & D1 & $1.10 \pm 0.2^{a}$ & $5.32 \pm 0.1^{b}$ & $6.84 \pm 0.3^{b}$ \\
\hline & & D2 & $0.98 \pm 0.1^{a}$ & $4.68 \pm 0.1^{b}$ & $6.28 \pm 0.3^{a, b}$ \\
\hline & & D3 & $1.22 \pm 0.1^{\mathrm{a}}$ & $4.16 \pm 0.2^{b}$ & $4.66 \pm 0.1^{b}$ \\
\hline
\end{tabular}

Biochemical analysis between diabetic and control groups at $2^{\text {nd }}$ week of treatment and $3^{\text {rd }}$ week of induction

Serum insulin concentrations were increased significantly in group 2 as well as group 3 compared with those of control values in group 1, whereas its concentrations in (insulin + herbal therapy, group 3) treated animals were significantly higher and reach its normal peak than those of (group 2) treated with insulin only $(P<0.05$; Table 4). Serum glucose concentrations in (group 3) were significantly decreased in D1 and D2 of $2^{\text {nd }}$ week of treatment compared to (group 2) or control (group 1) ( $P<0.05$; Table 4). Serum enzymatic activities of liver including (ALP, AST and ALT) and serum albumin during $2^{\text {nd }}$ week of treatment. ALP, AST and ALT concentrations were significantly increased in D1 in diabetic groups in comparing with control group at $1^{\text {st }}$ week of induction. Also the previous parameters were significantly lower and return to their normal concentrations in D2 in treated group with insulin + herbal therapy than treated one with insulin only $(P<0.05$; Table 4). Serum albumin concentrations was significantly higher in both diabetic groups at D1 compared to control group, but were not significantly different at D2 compared to control group as it back to its normal concentrations in both treated group ( $P>0.05$; Table 4). Triglycerides and cholesterol were significantly lower in dogs treated with (insulin + herbal therapy) in D1 and D2 compared to control group and the one treated with insulin only. Serum LDL concentrations were elevated in both diabetic groups significantly than those of the control normal group. But, the increase concentrations in group treated with herbal therapy was significantly lower than those diabetic group treated with insulin only. Serum HDL concentrations were lower in both diabetic groups than control group. But, its concentration in dogs treated with (insulin + herbal therapy) at D2 was significantly higher than those treated with insulin only $(P<0.05)$. SAA concentrations were not significantly different between groups of dogs at D1 and D2 as it back to normal values 
( $P>0.05)$. However, CRP and HP concentrations were elevated significantly in two treated groups of dogs at D1 compared to control group. But the elevation in HP and CRP concentrations in treated group with insulin+ herbal therapy were significantly lower than treated group with insulin only at D2 $(P<0.05$; Table 4). Insulin concentrations were increased, while glucose concentrations were decreased in insulin with herbal therapy treated group compared with insulin treated group $(P<0.05$; Figure 1). Other biochemical parameters and acute phase proteins were closely return to normal level significantly in insulin with herbal therapy compared with insulin treated group $(P<0.05$; Figures 2 and 3$)$.

\section{Table 4 - Biochemical analysis between diabetic and control groups at $2^{\text {nd }}$ week of treatment and 3 rd week of induction}

\begin{tabular}{|c|c|c|c|c|c|}
\hline \multirow[b]{2}{*}{ Variables } & \multirow[b]{2}{*}{ Weeks } & \multirow[b]{2}{*}{ Days } & \multirow[b]{2}{*}{ Control } & \multicolumn{2}{|c|}{ After induction without treatment } \\
\hline & & & & Insulin & $\begin{array}{c}\text { Insulin with herbal } \\
\text { therapy }\end{array}$ \\
\hline \multirow{2}{*}{ Insulin $(\mu \mathrm{u} / \mathrm{mL})$} & \multirow{2}{*}{$3^{\text {rd }}$ week } & D1 & $10.20 \pm 0.70^{\mathrm{a}}$ & $7.40 \pm 0.2^{b}$ & $10.24 \pm 0.28^{b}$ \\
\hline & & D2 & $10.5 \pm 1.4$ a & $8.4 \pm 0.6^{b}$ & $11.4 \pm 1.2 \mathrm{a}, \mathrm{b}$ \\
\hline \multirow{2}{*}{ Glucose (mg/dL) } & \multirow{2}{*}{$3^{\text {rd }}$ week } & D1 & $92.20 \pm 5.6^{a}$ & $188.60 \pm 5.8^{b}$ & $170.80 \pm 2.0^{a, b}$ \\
\hline & & D2 & $96 \pm 2.4^{a}$ & $170 \pm 5.8^{b}$ & $145 \pm 3.7^{a, b}$ \\
\hline \multirow{2}{*}{$\operatorname{ALP}(u / L)$} & \multirow{2}{*}{$3^{\text {rd }}$ week } & D1 & $156.20 \pm 4.6^{a}$ & $224.40 \pm 7.4^{b}$ & $208.0 \pm 7.7^{b}$ \\
\hline & & D2 & $163 \pm 5.4^{a}$ & $205 \pm 4.2^{\mathrm{b}}$ & $176 \pm 7.6^{a}$ \\
\hline \multirow{2}{*}{ AST $(u / L)$} & \multirow{2}{*}{$3^{\text {rd }}$ week } & D1 & $32.20 \pm 3.2^{a}$ & $60.80 \pm 2.7^{b}$ & $39.20 \pm 2.08^{b}$ \\
\hline & & D2 & $33 \pm 1.3$ a & $54 \pm 2.5^{b}$ & $36 \pm 2.8 \mathrm{a}, \mathrm{b}$ \\
\hline \multirow{2}{*}{$\operatorname{ALT}(\mathrm{u} / \mathrm{L})$} & \multirow{2}{*}{$3^{\text {rd }}$ week } & D1 & $31.60 \pm 2.24^{a}$ & $75.80 \pm 3.4^{b}$ & $48.0 \pm 2.5^{a, b}$ \\
\hline & & D2 & $32 \pm 1.6$ a & $67 \pm 0.2^{\mathrm{b}}$ & $39 \pm 0.4^{a, b}$ \\
\hline \multirow{2}{*}{ Albumin (mg/dL) } & \multirow{2}{*}{$3^{\text {rd }}$ week } & D1 & $4.30 \pm 0.35^{a}$ & $5.24 \pm 0.26^{b}$ & $4.80 \pm 0.14^{b}$ \\
\hline & & D2 & $4.3 \pm 0.3$ a & $4.3 \pm 0.4$ a & $4.9 \pm 0.8$ a \\
\hline \multirow{2}{*}{ Triglycerides (mg/dL) } & \multirow{2}{*}{$3^{\text {rd }}$ week } & D1 & $111.40 \pm 4.2^{a}$ & $163.60 \pm 9.5^{b}$ & $137.0 \pm \quad 4.4^{\mathrm{a}, \mathrm{b}}$ \\
\hline & & D2 & $113 \pm 5.2^{\mathrm{a}}$ & $144 \pm 4.3^{b}$ & $117 \pm 6.4^{\mathrm{a}}$ \\
\hline \multirow{2}{*}{ Cholesterol (mg/dL) } & \multirow{2}{*}{$3^{\text {rd }}$ week } & D1 & $150.40 \pm 4.8^{a}$ & $197.4 \pm 4.2^{b}$ & $168.60 \pm 3.6^{a, b}$ \\
\hline & & D2 & $149 \pm 5.1$ a & $187 \pm 6.2$ b & $150 \pm 4.3$ a \\
\hline \multirow{2}{*}{$\mathrm{LDL}(\mathrm{mg} / \mathrm{dL})$} & \multirow{2}{*}{$3^{\text {rd }}$ week } & D1 & $74.20 \pm 3.3^{a}$ & $143.80 \pm 2.83^{b}$ & $123.40 \pm 3.31^{a, b}$ \\
\hline & & D2 & $73 \pm 1.2$ a & $131 \pm 2.6 \mathrm{~b}$ & $96 \pm 3.05^{\mathrm{a}, \mathrm{b}}$ \\
\hline \multirow{2}{*}{$\mathrm{HDL}(\mathrm{mg} / \mathrm{dL})$} & \multirow{2}{*}{$3^{\text {rd }}$ week } & D1 & $57.40 \pm 6.1^{a}$ & $45.7 \pm 3.5^{b}$ & $48.80 \pm 1.7^{b}$ \\
\hline & & D2 & $53 \pm 1.3$ a & $31 \pm 1.2^{\mathrm{a}, \mathrm{b}}$ & $48 \pm 2.6$ \\
\hline \multirow{2}{*}{$\mathrm{SAA}(\mu \mathrm{g} / \mathrm{mL})$} & \multirow{2}{*}{$3^{\text {rd }}$ week } & D1 & $5.36 \pm 0.32^{a}$ & $5.52 \pm 0.24^{a}$ & $5.66 \pm 0.12^{a}$ \\
\hline & & D2 & $5.2 \pm 0.1^{a}$ & $5.5 \pm 0.3^{a}$ & $5.3 \pm 0.7^{a}$ \\
\hline \multirow{2}{*}{ CRP (mg/L) } & \multirow{2}{*}{$3^{\text {rd }}$ week } & D1 & $4.10 \pm 0.47^{a}$ & $11.40 \pm 1.2^{b}$ & $9.0 \pm 1.4^{b}$ \\
\hline & & D2 & $4.2 \pm 0.3$ a & $9.8 \pm 1.2 \mathrm{~b}$ & $6.02 \pm 0.8 \mathrm{a}, \mathrm{b}$ \\
\hline \multirow{2}{*}{ Haptoglobin (g/L) } & \multirow{2}{*}{$3^{\text {rd }}$ week } & D1 & $1.08 \pm 0.24^{a}$ & $3.14 \pm 0.21^{b}$ & $2.78 \pm 0.08^{b}$ \\
\hline & & D2 & $0.8 \pm 0.5 \mathrm{a}$ & $2.5 \pm 0.6^{b}$ & $1.6 \pm 0.7^{a, b}$ \\
\hline
\end{tabular}

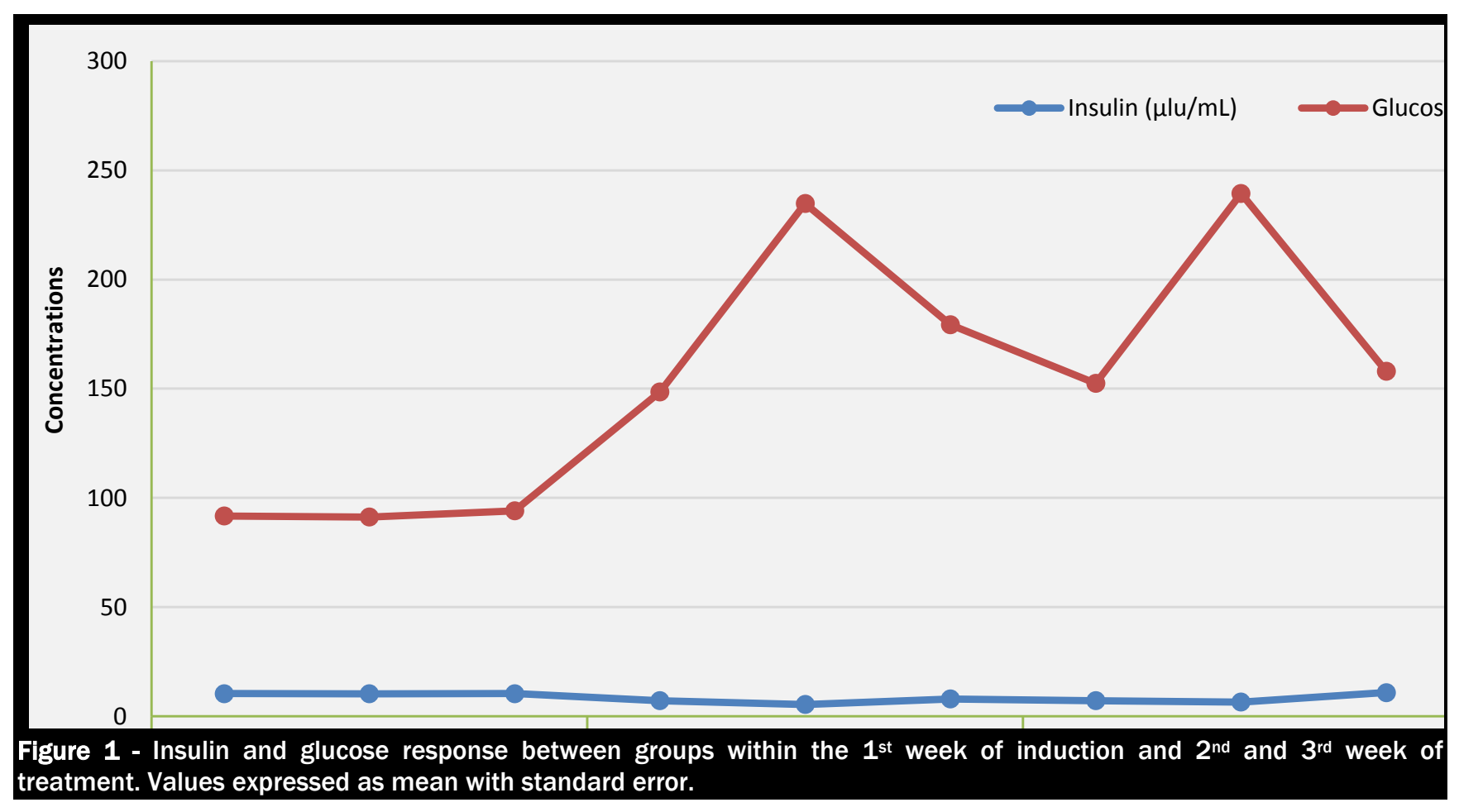




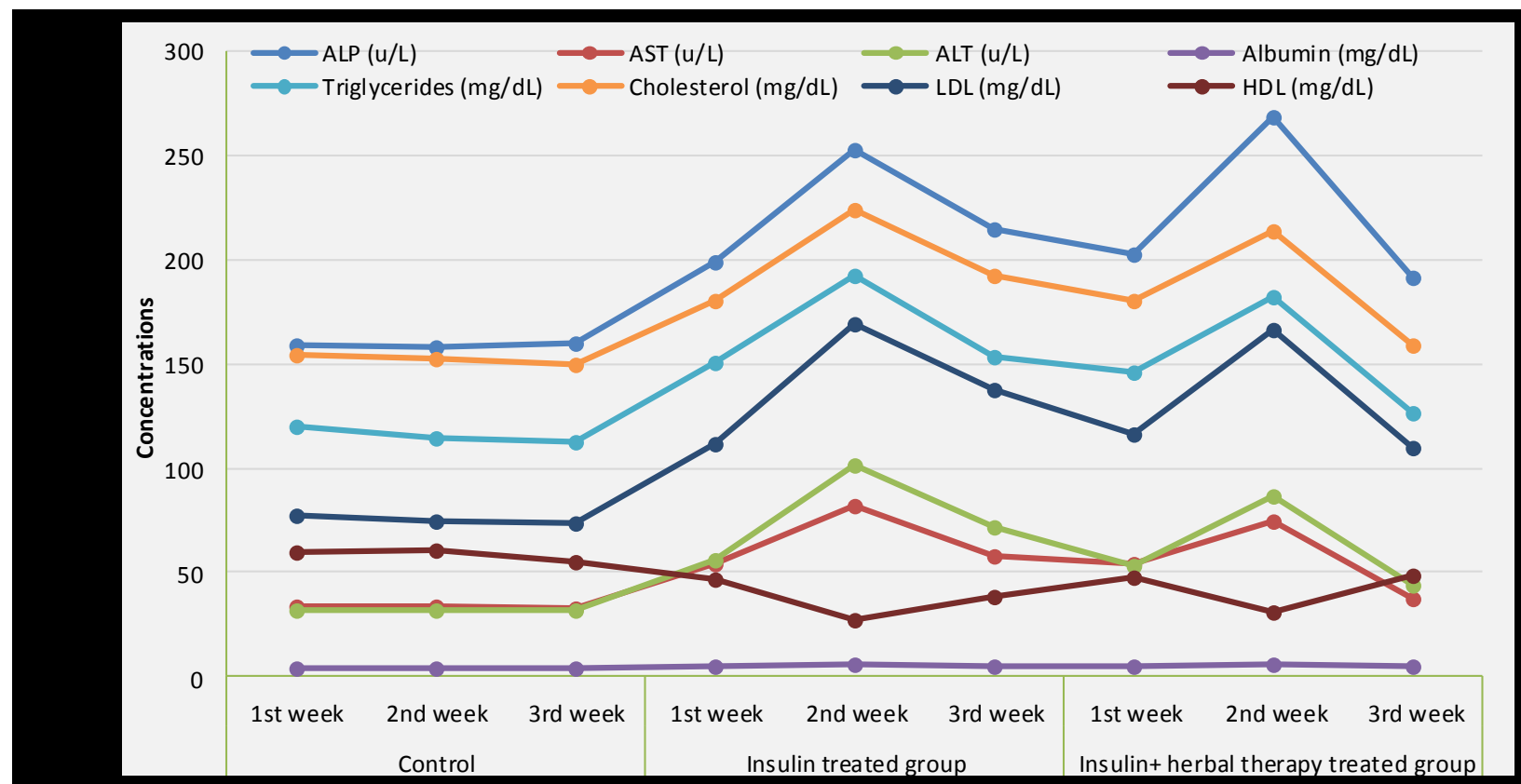

Figure 2 - Biochemical changes between groups within the $1^{\text {st }}$ week of induction and $2^{\text {nd }}$ and $3^{\text {rd }}$ week of treatment. Values expressed as mean with standard error.

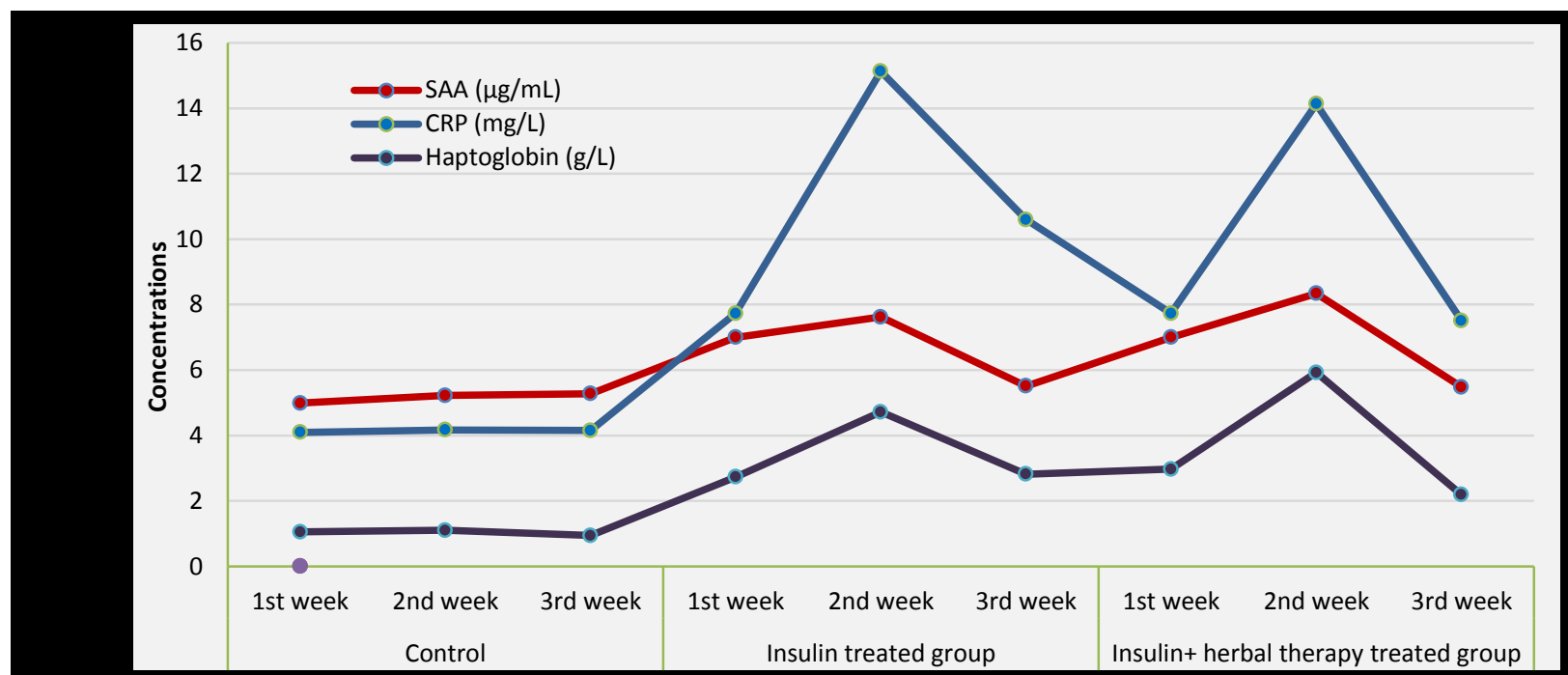

Figure 3 - Acute phase protein pattern between groups within the $1^{\text {st }}$ week of induction and $2^{\text {nd }}$ and $3^{\text {rd }}$ week of treatment. Values expressed as mean with standard error.
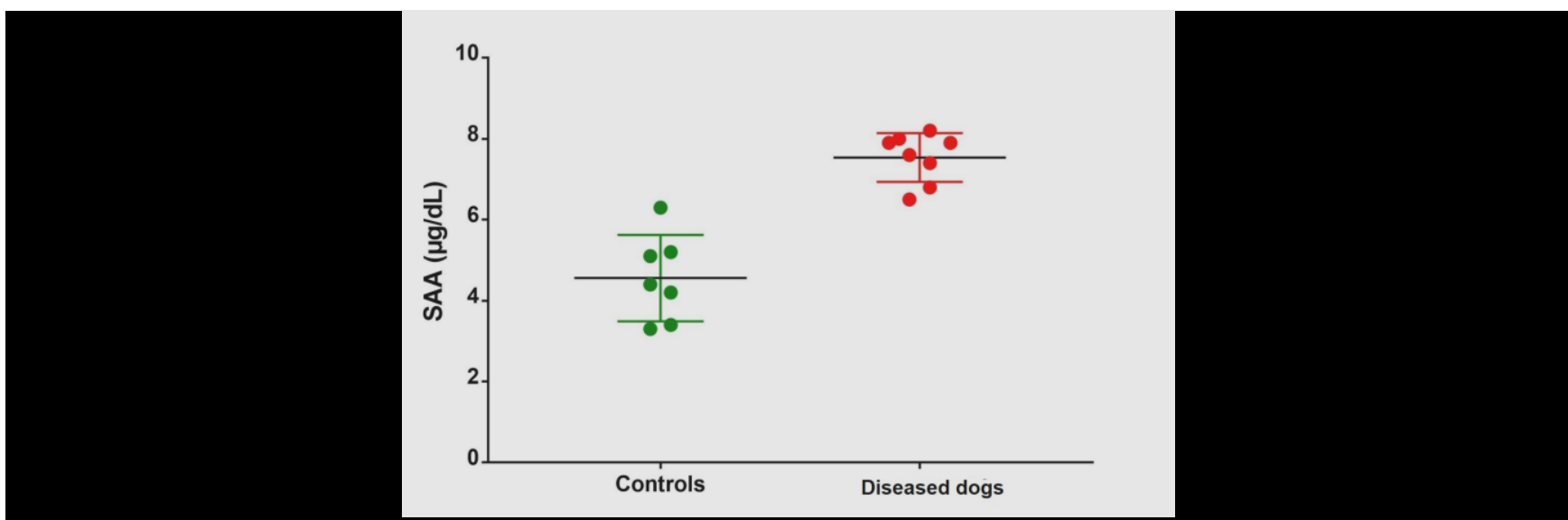

Figure 4 - SAA area under the curve $=0.955$ with sensitivity $=90 \%$ and specificity $=85 \%$ in dogs with serum amyloid A concentrations $=6.6 \mu \mathrm{g} / \mathrm{mL}$

Specificity and Sensitivity of acute phase proteins in dogs with experimentally induced diabetes mellitus

Serum amyloid A, c-reactive protein and haptoglobin concentrations were highly sensitive and specific in the diagnosis of dogs with induced diabetes mellitus with area under the curve (AUC) close to 1 with $P<0.05$ as shown in figure 4. 


\section{Histopathological finding}

Pancreatic tissue of dog from group 2 showed different pathological changes like sever congestion of blood vessels, sever coagulative necrosis of pancreatic acini either focal or diffuse, mononuclear cells infiltration between the pancreatic acini, some cells showed programed cell death (apoptosis). Finally, there was sever proliferation of connective tissue (Figure 5 A,B,C\&D). Pancreatic tissue of dog from group 3 showed less sever pathological changes represented as congested blood vessels mononuclear cells infiltration (Figure 5 E\&F). Hepatic tissue of dog from group 2 showed different pathological changes represented as dilated and congested central vein and hepatic sinusoids, proliferation of Kupffer cells, focal and diffuse mononuclear cells infiltration in the portal areas and hepatic parenchyma. There was also sever swelling of hepatocytes and focal areas of necrosis and mononuclear cells infiltration. The portal areas showed mononuclear cells infiltration and congested blood vessels with proliferation of connective tissue (Figure 6 A,B,C\&D). Hepatic tissue of dog from group 3 showed less sever changes represented as congested blood vessels and hepatic sinusoids, the hepatic tissue showed fatty change appeared as clear vacuoles in the hepatocytes, also there was single cell necrosis in the hepatic parenchyma (Figure $6 \mathrm{E} \& \mathrm{~F}$ ).
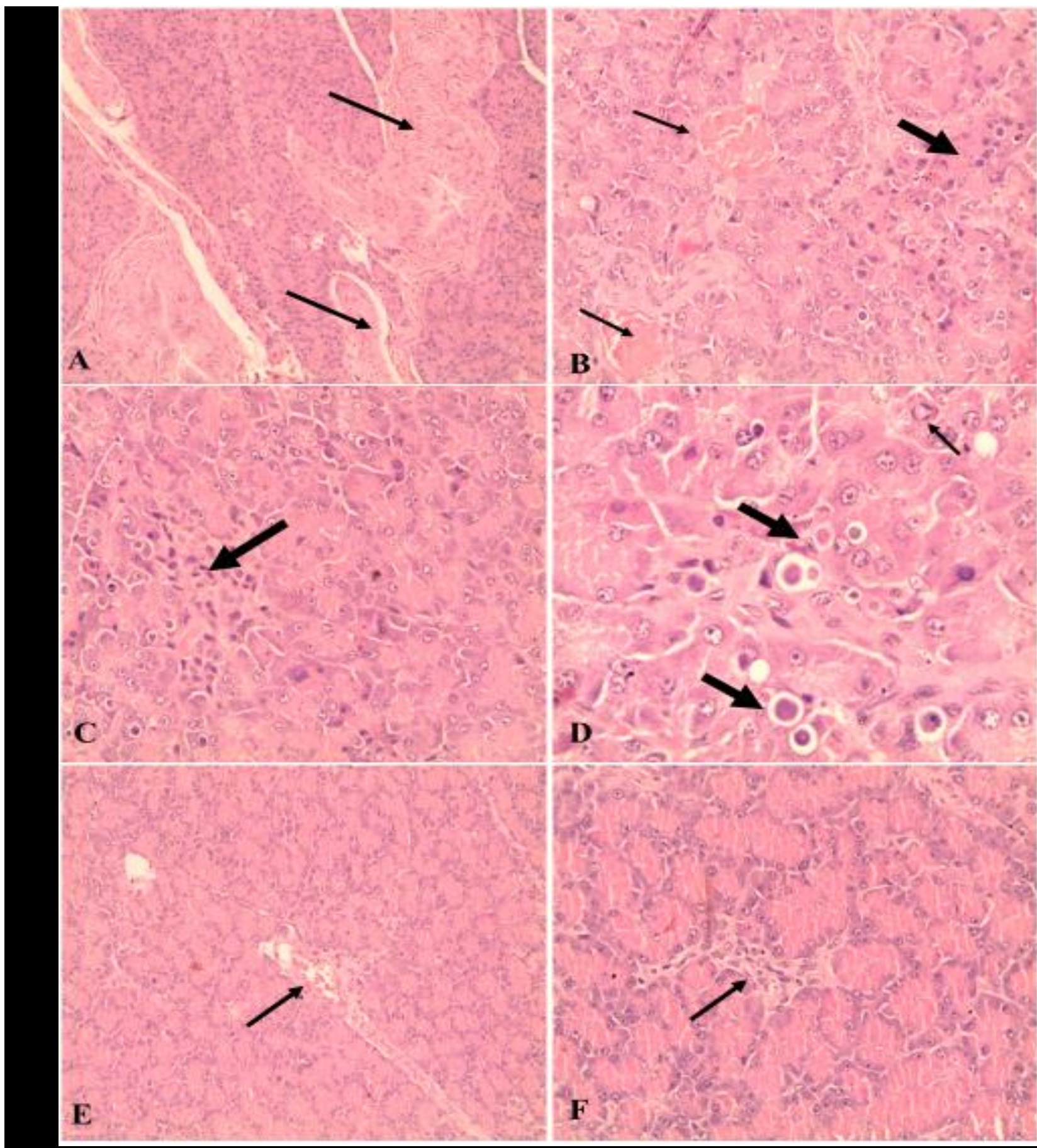

E

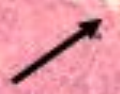

Figure 5 - A. Pancreas of dog from (group 2) showed sever fibrosis (arrow) with coagulative necrosis of pancreatic tissue (H\&E x 10); B. Pancreas of dog from (group 2) showed sever congestion of blood vessels (thin arrow) and sever coagulative necrosis of pancreatic acini (thick arrow) (H\&E x 20); C. Pancreas of dog from (group 2) showed focal area of necrosis with mononuclear cells infiltration (arrow) (H\&E x 20); D. Pancreas of dog from (group 2) showed apoptotic cells (thin arrow) and necrotic cells (thick arrow) (H\&E x 40); E. Pancreas of dog from (group 3) showed congested blood vessels (arrow) (H\&E x 10); F. Pancreas of dog from (group 3) showed mononuclear cells infiltration (arrow) (H\&E x 20). 


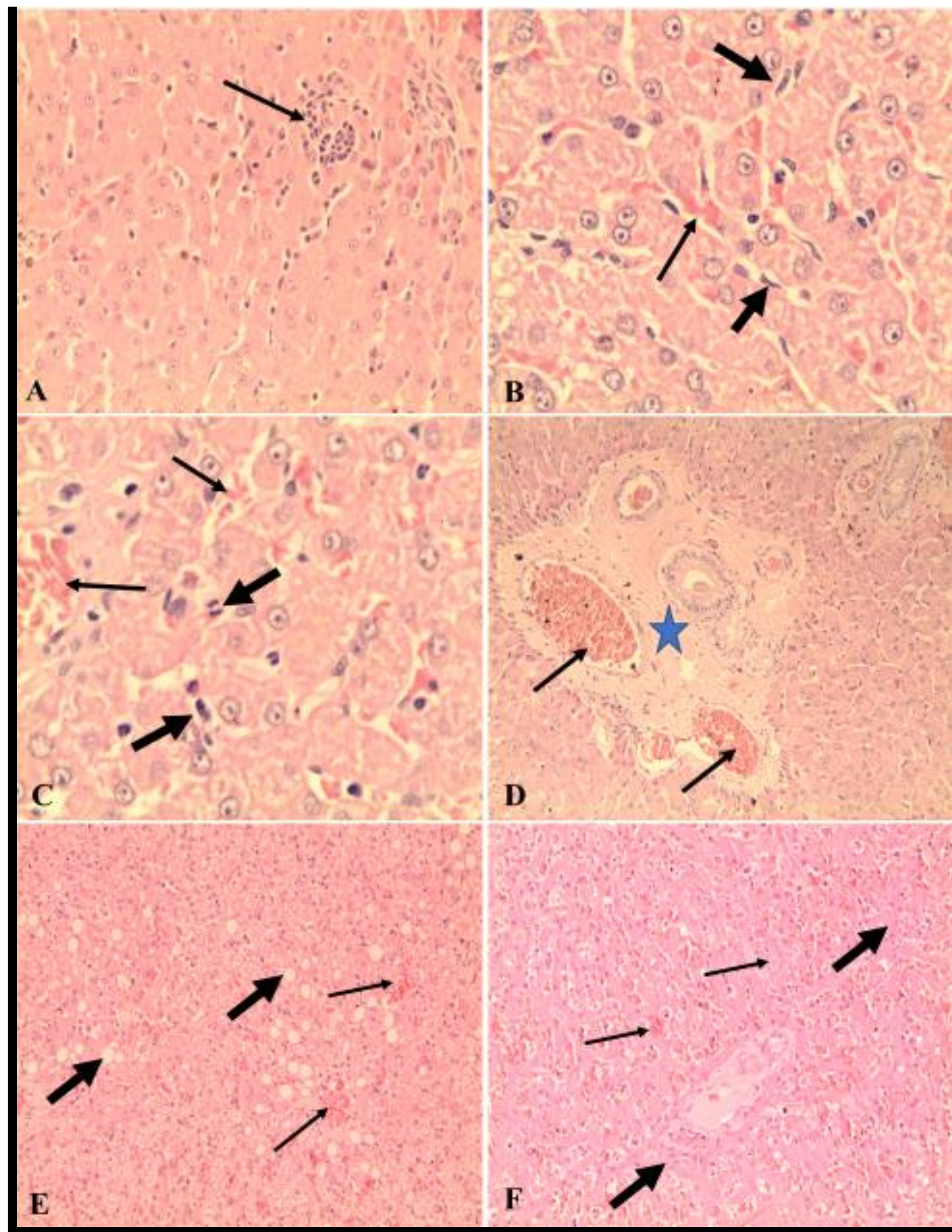

Figure 6 - A. liver of dog from (group 2) showed focal area of necrosis and mononuclear cells infiltration (arrow) (H\&E $x$ 20); B. liver of dog from (group 2) showed dilated and congested hepatic sinusoids (thin arrow) and proliferation of Kuepfer cells (thick arrow) (H\&E x 40); C. liver of dog from (group 2) showed congested blood vessels and hepatic sinusoids (thin arrow), diffuse mononuclear cells infiltration (thick arrow) and sever swelling of hepatocytes (H\&E x 40); D. liver of dog from (group 2) showed proliferation of connective tissue in the portal areas (star) with mononuclear cells infiltration and congested blood vessels (arrow) (H\&E x 10); E. liver of dog from (group 3) showed congested blood vessels and hepatic sinusoids (thin arrow) and the hepatocytes showed fatty change (thick arrow) (H\&E x 10); F. liver of dog from (group 3) showed severely congested blood vessels and hepatic sinusoids (thin arrow) and coagulative necrosis in hepatic parenchyma (thick arrow) (H\&E x 10). 


\section{DISCUSSION}

In the present study administration of single dose of alloxan $\left(35 \mathrm{mg} / \mathrm{kg}^{-1}\right)$ induced diabetes mellitus in dogs. One week after alloxan injection, the dogs showed polyuria, polydipsia and polyphagia. Some of these animals were suffered from vomition, dehydration and variable degrees of lethargy, partial anorexia and mild to moderate weight loss. These clinical signs were similar to those reported by Khoshvaghti and Heidi (2012) and Ismail et al. (2015).

There were a significant decrease in heart rate, and non-significant change in the body temperature, before and after the experimental induction of diabetes mellitus, our observations are in agreement with a previous study by Howarth et al. (2011) who revealed that heart rate declined rapidly after administration of alloxan. Serum analysis of alloxaninduced diabetic dogs showed significant increase in fasting blood glucose and decreased insulin concentrations compared to their concentrations before induction of diabetes. This result indicates that alloxan successfully induced DM in dogs as documented by Valilou and Lotfi (2012), Ismail et al. (2015) and Khanam and Dewan (2008).

The liver related enzymes ALT, AST, and ALP concentrations were significantly increased after diabetes induction at D2 and D3 of induction compared with control healthy group. These results were coincided with Valilou and Lotfi (2012), Bhargavi et al. (2015) and Shruthi et al. (2017) who found increase in the concentrations of liver enzymes due to leakage of this enzyme from liver cytosol to blood circulation due to hepatic damage also another suggested reason for increase in AST activity following diabetes is greater need for gluconeogenic substrate due to diabetic condition stated by Tanaka et al. (1988), although elevation of both enzymes ALT, AST concentrations may also reflect the damage of hepatic cells via injected alloxan stated by Joo-min Kim et al. (2006). On the other hand, Ismail et al. (2015) showed a progressive increase in serum concentration of ALP in DM dogs while serum concentrations of other liver enzymes such as AST and ALT were not changed significantly.

Serum concentrations of ALP, ALT and AST were significantly higher in insulin treated animal group compared to control $(P<0.05)$ after $2^{\text {nd }}$ week of treatment but there concentrations decreased significantly when compared to the $1^{\text {st }}$ week of induction. ALP, AST and ALT concentrations were significantly lower and return to their normal concentrations in D2 in treated group with insulin + herbal therapy group 3 than group 2 treated with insulin only $(P<0.05)$. These results indicated that the administration of insulin with herbal therapy to diabetic dogs was found to be effective in improving liver function tests than insulin treatment alone. These results were coincided with Masjedi et al. (2013), Asdaq (2015) and Johnson et al. (2015) who found a significant reduction in the activities of liver enzymes with garlic in diabetic rats. The protective effects of garlic extract may be associated with the inherent-antioxidant properties as shown by Rahman (2003).

The lipid profile parameters including, cholesterol, triglycerides and LDL were significantly increased after diabetes induction at D2 and D3 of induction compared with control healthy group. Furthermore, we documented that Triglycerides, Serum LDL concentrations and cholesterol were significantly reduced in (group 3) treated with (insulin + herbal therapy) in D1 and D2 compared to control group and (group 2) treated with insulin only. The administration of insulin with herbal therapy to the diabetic dogs was found to be more effective in lowering total cholesterol value, serum LDL concentrations and serum triglycerides value than in insulin administration only. Serum HDL concentrations were lower in both diabetic groups than control group. But, its concentration in (group 3) treated with (insulin + herbal therapy) at D2 was significantly higher than those of (group 2) treated with insulin only. These results were coincided with Masjedi et al. (2013) and Asdaq (2015) who reported significant reduction in triglycerides and total cholesterol with garlic administration in diabetic rats.

The concentrations of acute-phase proteins (APPs) include haptoglobin, C-reactive protein and serum amyloid A started to be elevated significantly at D2 and D3 of induction in (group 2) and (group 3) compared with control group. These results were in agreement with Eckersall, (1995) and Riaz (2015). CRP and HP concentrations were elevated significantly in two treated groups of dogs at D1 compared to control group, but their elevation in treated group with insulin+ herbal therapy (group 3) were significantly lower than treated group with insulin only (group 2) at D2. These results were agreement with Kumar et al. (2013).

Insulin-treated animals showed a significant decrease in blood glucose and increased insulin concentrations in alloxan-induced diabetic dogs in $2^{\text {nd }}$ week treatment. The results were coincided with Mosseri et al. (2000) and Moller (2001). Interestingly serum insulin concentrations were increased significantly in group 2 as well as group 3 compared with those of control values in group 1, whereas its concentrations in (insulin + herbal therapy) (group 3) treated animals were significantly higher and reach its normal peak than those of (group 2) treated with insulin only $(P<0.05)$. This result was in agreement with Londhe et al. (2011) who found that Allicin is one of active chemical constituent of garlic that raise the serum insulin concentrations. Additionally, serum glucose concentrations in (group 3) were significantly decreased in D1 and D2 of 2nd week of treatment compared to (group 2) or control (group 1). The administration of insulin with herbal therapy to diabetic animals was found to be more effective in lowering blood glucose concentrations than insulin administration alone. This result agreement with Kumar et al., (2013), Masjedi et al. (2013) and johnson et al. (2015) who found that garlic showing a significant decrease in serum glucose concentrations alone or in combination with either antidiabetic drugs or other herbal therapy.

The histopathological examination of the pancreas of alloxan-induced diabetic dogs treated with insulin plus herbal therapy (group 3) revealed less sever pathological changes compared with (group 2) treated with insulin only, represented as congested blood vessels mononuclear cells infiltration. 
The histopathological examination of the pancreas of insulin treated group revealed sever congestion of blood vessels, sever coagulative necrosis of pancreatic acini either focal or diffuse, mononuclear cells infiltration between the pancreatic acini, some cells showed programed cell death (apoptosis). Finally, there was severing proliferation of connective tissue. These histopathological finding were coincided with Joo-Min Kim et al. (2006), Khanam and Dewan (2008) and Ismail et al. (2015). Moreover, The histopathological examination of the liver of insulin treated group revealed different pathological changes represented as dilated and congested central vein and hepatic sinusoids, proliferation of Kupffer cells, focal and diffuse mononuclear cells infiltration in the portal areas and hepatic parenchyma. There was also sever swelling of hepatocytes and focal areas of necrosis and mononuclear cells infiltration. The portal areas showed mononuclear cells infiltration and congested blood vessels with proliferation of connective tissue These finding were consistent with these reported by Joo-Min Kim et al. ( 2006), Khanam and Dewan (2008) and Ismail et al. (2015).

Of interest, The histopathological examination of the liver of alloxan-induced diabetic dogs treated with insulin plus herbal therapy (group 3) revealed less sever pathological changes compared with (group 2) treated with insulin only, represented as congested blood vessels and hepatic sinusoids, the hepatic tissue showed fatty change appeared as clear vacuoles in the hepatocytes, also there was single cell necrosis in the hepatic parenchyma. These results were agreement with Masjedi et al. (2013) who conclude that the inhibition of morphology and histomorphometrical changes in the pancreas and the better improvement in liver tissue were dramatically decreased due to garlic juice administration are considered to be the direct evidence that garlic juice improves diabetes. Also there was an improvement in the microscopic picture of examined pancreas, liver and kidney in diabetic rates treated with Trigonella foenum by Abou ElSoud et al. (2007) who mentioned that the hepatic lobules appeared more or less like control and Kanter et al. (2004) who founded NS treatment has been provide a protective effect by decreasing lipid peroxidation and serum NO, and increasing antioxidant enzyme activity. Islet cell degeneration and weak insulin immunohistochemical staining was observed in rats with STZ-induced diabetes. Increased intensity of staining for insulin, and preservation of beta-cell numbers were apparent in the NS-treated diabetic rats. These findings suggest that NS treatment exerts a therapeutic protective effect in diabetes by decreasing oxidative stress and preserving pancreatic beta-cell integrity. Consequently, NS may be clinically useful for protecting beta-cells against oxidative stress. This study has a limitation lacking of day $3^{\text {at }} 2^{\text {nd }}$ week of treatment and 3rd week of induction.

\section{CONCLUSION}

Acute-phase proteins (APPs) can be used as diagnostic biomarkers in DM and early acute pancreatitis. Moreover, the therapeutic effects of the medical plants like (Garlic, Fenugreek and Black seeds) were increased the potency and glycemic control of insulin in animals with diabetes mellitus. Therefore these plants are recommended to be used for treatment of DM in animals because of their hypoglycemic effect. However, this study has a limitation lacking of group of animals treated with herbal therapy, this study could give a future support for using of herbal therapy as potential medicine beside insulin to control diabetes mellitus in dogs.

\section{DECLARATIONS}

Acknowledgments

Our grateful thanks to all veterinarian and technical staff at the Faculty of Veterinary Medicine, the University of Sadat city for their support in this study.

Author's contribution

All authors were contributed equally in this study

Competing interests

The authors declare that they have no competing interests.

Conflict of interest

The authors declared that no conflict of interest

Corresponding Author

E-mail: Hanyhassan1959@gmail.com; ORCiD: https://orcid.org/0000-0002-8967-7362

\section{REFERENCES}

Abou El-Soud NH, Khalil MY, Hussein JS, Oraby FSH and Farrag ARH, (2007). Antidiabetic effects of fenugreek alkaloid extract in streptozotocin induced hyperglycemic rats. Journal of Applied Sciences Research, 3 (10): 1073 - 1083. (Google Scholar; Import into EndNote)

Atila G and Yuce A (2016). Effects of the Trigonella foenum-graecum L. seed extract and chromium picolinate supplementation in streptozotocin induced diabetes in rats. Indian Journal of Traditional Knowledge, 15(3): 447-452. (Google Scholar; Import into EndNote) 
Bhargavi G, Josthna P and Naidu CV, (2015). Antioxidant properties of polyalthia cerasoides stem bark extract on streptozotocin induced diabetic rats. European Journal of Biomedical and Pharmaceutical Sciences. 2 (3): 640-652. (Google Scholar; Import into EndNote)

Brenner K, Harkin KR, Andrews GA and Kennedy G, (2009). Juvenile Pancreatic Atrophy in Greyhounds: 12 Cases (1995 -2000). Journal of Veterinary Internal Medicine. 23:67-71. (Google Scholar; Import into EndNote)

Cero'n JJ, Eckersall PD and Martnez-Subiela S, (2005). Acute phase proteins in dogs and cats: current knowledge and future perspectives.Veterinary Clinical Pathology 34:85-99. (Google Scholar; Import into EndNote)

Christopher MJ, Rantzau C and Alford FP, (2006). The relationship between peripheral glucose utilisation and insulin sensitivity in the regulation of hepatic glucose production: studies in normal and alloxan-diabetic dogs. Diabetes Metabolism Research and Reviews. 22: 155-167. (Google Scholar; Import into EndNote)

Eckersall PD, (1995). Acute phase proteins as markers of inflammatory lesions. Comparative Haematology International. 5:93-97. (Google Scholar; Import into EndNote)

Ettinger SJ, Feldman EC and Côté E, (2017). Canine diabetes mellitus. In: Textbook of Veterinary Internal Medicine. SJ Ettinger and EC Feldman (eds). 8th edition. Elsevier, St Louis, Missouri, 2017 (pp1767-1781). (Google Scholar; Import into EndNote)

Fransson BA, Bergstrom A, Wardrop $\mathrm{kJ}$ and Hagman R, (2007). Assessment of three automated assays for C-reactive protein determination in dogs. American Journal of Veterinary Research, v.68:1281-1286. (Google Scholar; Import into EndNote)

Henderson AR and Donald WM, (2001). Enzymes, Tietz Fundamentals of Clinical Chemistry, 5th Ed., Burtis, C.A. \& Ashwood, E.R. (W.B. Saunders eds. Philadelphia USA), 352. (Google Scholar; Import into EndNote)

Hess RS and Ward CR, (2000). Effect of insulin dosage on glycemic response in dogs with diabetes mellitus: 221 cases (1993-1998). Journal of American Veterinary Medical Association. 15; 216(2):217-21. (Google Scholar; Import into EndNote)

Howarth FC, Jacobson M, Shafiullah M, Ljubisavljevic M and Adeghate E, (2011). Heart rate, body temperature and physical activity are variously affected during insulin treatment in alloxan-induced type 1 diabetic rat. Physiology Research. 60: 65-73. (Google Scholar; Import into EndNote)

Ismail ZB, Hananeh W, Alshehabat M, Daradka M and Ali J, (2015). Short -term clinical and pathological alterations associated with a single intravenous injection of alloxan monohydrate in dogs. Human and Veterinary Medicine Bioflux; 7(2):70-74. (Google Scholar; Import into EndNote)

Jitpean S, Pettersson A, Höglund OV, Holst BS, Olsson U and Hagman R, (2014). Increased concentrations of Serum amyloid A in dogs with sepsis caused by pyometra. BMC Veterinary Research, 10, 273. https://dx.doi.org/10.1186/s12917-014-0273-9. (Google Scholar; Import into EndNote)

Johnson OR, Emeka OP and Femi BP, (2015). Comparative effect of daily administration of allium sativum and allium cepa extracts on alloxan induced diabetic rats. IOSR Journal of Biotechnology and Biochemistry (IOSR-JBB). 1(2): 26-31. (Google Scholar; Import into EndNote)

Joo-min Kim, Jun-Young Chung, Sook-yeon lee, Eun-Whachoi, Min-kyukim, Cheo-young Hwong and Hwa-Young youn, (2006). Hypoglycemic effect of vanadium on alloxan monohydrate induced diabetic dogs. Journal of Veterinary Science, 7(4): 391-395. (Google Scholar; Import into EndNote)

Kanter M, Coskun 0, Korkamz A and Oter S, (2004). Effects of nigella sativa on oxidative stress and $\beta$-cells damage in streptozotocininduced diabetic rats. The anatomical record part A. Wiley-LISS, INC 279A:685-691. (Google Scholar; Import into EndNote)

Kaplan AU and Kaplan A, (1984). Clin Chem The C.V. Mosby Co. St Louis. Toronto. Princeton: 1257-1260 and 437 and 418.

Khanam M and Dewan ZF, (2008). Effects of the crude and the n-hexane extract of nigella sativa Linn. (kalajira) upon diabetic rats. Bangladesh Journal of Pharmacology; 4:17-20. (Google Scholar; Import into EndNote)

Khoshvaghti A and Hamidi AR, (2012). Comparative effects of oral administration of Citrullus colocynthis and insulin injection on serum biochemical parameters of alloxan-induced diabetic dogs. Comparative Clinical Pathology. 21:1337-1341. (Google Scholar; Import into EndNote)

Kumar K, Kumar S, Datta A and Bandyopadhyay A, (2015). Effect of fenugreek seeds on glycemia and dyslipidemia in patients with type 2 diabetes mellitus. International Journal of Medical Science and Public Health, Vol 4, Issue 7. (Google Scholar; Import into EndNote)

Kumar R, Chhatwal S, Arora S, Sharma S, Singh J, Singh N, Bhandari V and Khurana A, (2013). Antihyperglycemic, antihyperlipidemic, antiinflammatory and adenosine deaminase lowering effects of garlic in patients with type 2 diabetes mellitus with obesity. Diabetes, Metabolic Syndrome and Obesity. 6: 49-56. (Google Scholar; Import into EndNote)

Londhe VP, Gavasane AT, Nipate, SS, Bandawane DD and Chaudhari PD, (2011). Role of garlic (Allium sativum) in various diseases: an overview. J Pharm Research Opinion. 1(4): 129-134. (Google Scholar; Import into EndNote)

Masjedi F, Gol A and Dabiri S, (2013). Preventive Effect of Garlic (Allium sativum L.) on Serum Biochemical Factors and Histopathology of Pancreas and Liver in Streptozotocin-Induced Diabetic Rats. Iranian Journal of Pharmaceutical Research, 12(3): 325-338. (Google Scholar; Import into EndNote)

Mathura ML, Gaura J, Sharmaa R and Haldiyaa KR, (2011). Antidiabetic Properties of a Spice Plant Nigella sativa. Journal of Endocrinology and Metabolism. 1(1):1-8. (Google Scholar; Import into EndNote)

Meiattini F, Prencipe L, Bardelli F, Giannini G and Tarli P, (1978). The 4-hydroxybenzoate/4-aminophenazone chromogenic system used in the enzymic determination of serum cholesterol. Clinical Chemistry. 24(12):2161-5. (Google Scholar; Import into EndNote)

Mesa MG, (2014). Antidiabetic potential of plants used in Cuba. Pharmacologyonline, 1:52-62. (ResearchGate)

Moller DE, (2001). New drug targets for type 2 diabetes and metabolic syndrome. Nature, 414, 821-827. (Google Scholar; Import into EndNote)

Mosseri R, Waner T, Shefi M, Shafrir E and Meyerovitch J, (2000). Gluconeogenesis in non-obese diabetic (NOD) mice: In Vivo Effects of vanadate treatment on hepatic glucose- 6- phosphatase and phosphoénol pyruvate carboxykinase. Metabolism. 49: 321-325. (Google Scholar; Import into EndNote)

Nelson RH and Reusch CE, (2014). Classification and etiology of diabetes in dogs and cats. DOI: https://dx.doi.org/10.1530/JOE-14-0202. Journal of Endocrinology, 222: T1-T9. (Google Scholar; Import into EndNote)

Nevalainen PI, Lahtela JT, Mustonen J, Marja-Riitta Taskinen M and Pasternack A, (1999). the effect of insulin delivery route on lipoproteins in type I diabetic patients on CAPD. Peritoneal Dialysis International, 19: 148-153. (Google Scholar; Import into EndNote) 
Patel P, Harde P, Pillai J, Darji N and Patel B, (2012). Antidiabetic herbal drugs a review. Pharmacophore, 3 (1): 18-29. (Google Scholar; Import into EndNote)

Rafael AC, Mario R and García-Palmieri, (1990). Clinical Methods: The History, Physical, and Laboratory Examinations. $3^{\text {rd }}$ edition (https://www.ncbi.nIm.nih.gov/books/NBK351/ PMID: 21250192).

Rahman K, (2003). Garlic and aging: A new insights into an old remedy. Ageing Research Reviews; 2: 39-56. (Google Scholar; Import into EndNote)

Reitman S and Frankel S, (1957). A colorimetric method for determination of serum glutamate oxaloacetate and glutamic pyruvate transaminase. American Journal of Clinical Pathology. 28: 56-58. (Google Scholar; Import into EndNote)

Riaz S, (2015). Study of Protein Biomarkers of Diabetes Mellitus Type 2 and Therapy with Vitamin B1. Journal of Diabetes Research, Article ID 150176, 10 pages. (Google Scholar; Import into EndNote)

Rucinsky R, Cook A, Haley S, Nelson R, Zoran DL and Poundstone M, (2010). American Animal Hospital Association AAHA diabetes management guidelines. Journal of American Animal Hospital Association. 46(3): 215-224. (Google Scholar; Import into EndNote)

Sahinduran S, Albay MK, Karakurum MC, Ozmen $O$ and Kale M, (2016). Investigation of Some Cytokines, Acute Phase Proteins and Hepcidin Concentrations Before and After Treatment in Dogs with Parvoviral Gastroenteritis. Pakistan Veterinary Journal, 36(4), 487 492. (Google Scholar; Import into EndNote)

Shruthi JS, Ramesh PT and Umesh KG, (2017). Hemato-Biochemical alterations in canine diabetes mellitus with special reference to glycated hemoglobin as a diagnostic tool. International Journal of Advanced Biological Research, 7 (2): $318-321$. (http://scienceandnature.org/IJABR_Vol7(2)2017/IJABR_V7(2)17-25.pdf)

Tanaka K, Nanbara S, Tanaka T, Koide H and Hayashi T, (1988). Aminotransferase activity in the liver of diabetic mice. Diabetes Research and Clinical Practice. 19: 71-75. (Google Scholar; Import into EndNote)

Thomas C and Richter GW, (1984). Sandritter's colour atalas and text book of histopathology. $7^{\text {th }}$ English ed., p: 1-4, year book medical publisher. Chicago. (Google Scholar; Import into EndNote)

Ti zhang, Yulong Huang, Tiande Hou and Yunpu Wang, (2006). hypoglycaemic effect of Artemisia sphaerocephala Krasch seed polysaccharide in alloxan-induced diabetic rats. Swiss MED wkly; 136: 529-532. (Google Scholar; Import into EndNote)

Trinder p, (1969). Determination of glucose in blood using glucose oxidase with an alternative oxygen receptor. Annals of Clinical Biochemistry. 6: 24. (Google Scholar; Import into EndNote)

Tvarijonaviciute A, García-Martínez JD, Caldin M, Martínez-Subiela S, Tecles F, Pastor Jand Ceron JJ, (2015). Serum paraoxonase 1 (PON1) activity in acute pancreatitis of dogs. Journal of Small Animal Practice, 56: 67-71. (Google Scholar; Import into EndNote)

Valilou MR and Lotfi AR, (2012). Changes in body weight and serum biochemical measures of German shepherd dogs following alloxan induced diabetes mellitus. Asian Journal of Biochemistry; 7:232-236. (Google Scholar; Import into EndNote)

Webster D, (1974). A study of the interaction of BCG with isolated globulin fractions. Clinica Chemica Acta. 1974. 53: 109-115. (Google Scholar; Import into EndNote)

Wilson MAand Miles LEM, (1977). Radioummuno assay of insulin. In "Hand book of radioimmuno assay". G.E. Abraham ed., M. Dekker Inc., New York, p. 275. (Google Scholar; Import into EndNote)

Young DS, (1990). Effects of drugs on clinical laboratory tests. Third edition. AACC Press, Washington DC, 104-106. 